\title{
Five years of specialised early intervention versus two years of specialised early intervention followed by three years of standard treatment for patients with a first episode psychosis: randomised, superiority, parallel group trial in Denmark (OPUS II)
}

\section{(ब) (1) $\Theta$ OPEN ACCESS}

In this article by Nikolai Albert and colleagues, several errors occurred during the editorial process (BMJ 2017;356:i6681, doi:10.1136/bmj.i6681).

The author Jens Richardt Mollegaard Jepsen is also affiliated to "Child and Adolescent Mental Health Centre, Mental Health Services Capital Region of Denmark, University of Copenhagen, Copenhagen, Denmark."

The first sentence of the online abstract's results section should read: "Levels of negative symptoms did not differ between the intervention group and control group (1.72 v 1.81 points; estimated mean difference -0.10 ( $95 \%$ confidence interval -0.33 [not " 0.33 "] to 0.13), $\mathrm{P}=0.39$ )." Likewise, the first sentence of the print abstract's results section should read "There was no difference between study groups on levels of negative symptoms
(1.72 v 1.81 points; estimated mean difference -0.10 (95\% confidence interval -0.33 [not " 0.33 "] to 0.13 ), $\mathrm{P}=0.39$ )."

The last sentence of the penultimate paragraph in the main text's results section should read: "For the working alliance exploratory outcome (estimated mean difference $5.56(95 \%$ confidence interval 2.30 to 8.82 ), $\mathrm{P}=0.001$; table 3 [not "table 2"]) and the client satisfaction secondary outcome (2.57 (1.36 to 3.79), $\mathrm{P}<0.001$; table 2 [not "table 3"]), we found a significant difference favouring OPUS treatment."

Finally, the first sentence of the funding section should read: "This study was funded by the Danish Agency for Science and Technology and Innovation and the TrygFonden (7-10-1057)." The funding section in the print abstract should also have included the details "TrygFonden (7-10-1057)."

We apologise for these errors. 